\title{
Uso da cutina na estimativa das digestões total e parcial de alguns componentes de rações contendo diferentes fontes de nitrogênio, em bovinos ${ }^{1}$
}

\author{
Leandro das Dores Ferreira da Silva ${ }^{2}$, Jane Maria Bertocco Ezequiel ${ }^{3}$, Paulo Sérgio de \\ Azevedo ${ }^{4}$, José Wanderley Cattelan ${ }^{3}$, Edson Luis de Azambuja Ribeiro ${ }^{2}$, Marco Antônio da \\ Rocha ${ }^{2}$, Valdecir de Souza Castro ${ }^{5}$, Ana Rosália Mendes ${ }^{4}$
}

\author{
1 Parte da tese de Doutorado do primeiro autor, apresentada a FCAVJ - UNESP. \\ 2 Departamento de Zootecnia/CCA. Universidade Estadual de Londrina. Rodovia Celso Garcia Cid s/n. Londrina, PR. \\ ${ }^{3}$ Departamento e Zootecnia - FCAVJ - UNESP, Campus de Jaboticabal, SP. \\ ${ }^{4}$ Doutores pela UNESP, Campus de Jaboticabal, SP. \\ 5 Graduação em Zootecnia, Bolsista PIBIC/CNPq /CCA. Universidade Estadual de Londrina, PR.
}

RESUMO - Seis novilhos Holandês x Zebu canulados no rúmen e no abomaso foram alimentados com rações contendo dois níveis de casca de soja e três fontes protéicas para determinação das digestões total e parcial no rúmen e nos intestinos. A cutina foi utilizada como indicador interno para se quantificarem a MS da digesta abomasal e a matéria seca fecal. Após 15 dias de adaptação dos animais às rações e às condições experimentais, foram coletadas 12 amostras por animal e por período das digestas do abomaso e das fezes. Foram determinados os teores de cutina, MS, MO, PB, FDN, FDA e CNF nas amostras compostas por animal e por período experimental. Não foram observados efeitos das fontes protéicas sobre as quantidades de MS, MO, FDN, FDA e PB no rúmen, no abomaso e no intestino. A amiréia proporcionou maiores ingestões de CNF e menores coeficientes de digestibilidades da MS, FDN, FDA e de CNF que as demais fontes protéicas. À exceção da PB, o teor de casca de soja afetou positivamente a digestão desses componentes no trato digestivo total e no rúmen. Os resultados indicaram potencial da cutina como indicador da taxa de passagem dos componentes nutritivos ao longo do trato digestivo.

Palavras-chave: amiréia, casca de soja, farelo de soja, indicador, matéria seca

\section{Use of cutine to estimate ruminal, intestinal, and total tract digestibilities of nutrients in steers fed different protein supplements}

\begin{abstract}
Six Holstein $x$ Zebu steers fitted with ruminal and abomasal cannulas and fed diets containing two levels of soybean hulls and three different protein supplements were used to determine ruminal, intestinal, and total tract digestibilities of nutrients. Cutine was used as the internal marker to quantify DM contents of both abomasal digesta and feces. After 15 days of diet adaptation, twelve samples of abomasal digesta and feces were taken from each animal in each period. Contents of cutine, DM, OM, CP, NDF, ADF, and NFC were all determined in samples that were pooled for animal and period. No significant differences in the amounts of ruminal, abomasal, and intestinal DM, OM, NDF, $\mathrm{ADF}$, and $\mathrm{CP}$ were observed among protein supplemnts. Feeding starea to steers resulted in higher intake of NFC but lower $\mathrm{DM}, \mathrm{NDF}, \mathrm{ADF}$, and NFC digestibility coefficients compared to the other protein supplements. Increasing soybean hulls levels in the diet also increased apparent ruminal and total tract digestibilities of all nutrients excepting crude protein in the rumen. It can be concluded that cutine can potentially be used as an internal marker to estimate passage rate of nutrients in the gastrointestinal tract of ruminants.
\end{abstract}

Key Words: dry matter, marker, soybean hulls, soybean meal, starea

\section{Introdução}

A digestibilidade de um alimento é uma das variáveis mais importantes para o conhecimento de seu valor nutricional, mas sua determinação in vivo com coleta total de excretas é muito dispendiosa, principalmente em grandes ruminantes. Por outro lado, a digestibilidade calculada pela técnica in vitro está sujeita a maiores fontes de erros, em razão das dificuldades em simulá-la às condições in vivo, sujeitas aos efeitos de consumo, às variações na taxa de passagem da digesta, à taxa de absorção de nutrientes e às suas inter-relações. Neste caso, torna-se importante o estudo de indicadores que façam parte dos constituintes naturais da dieta, por permanecerem distribuídos uniformemente na digesta ao longo do trato digestivo, desde sua ingestão até a excreção.

A cutina é um polímero ligado à parede celular, utilizado como indicador, mas com poucas informações na literatura 
sobre as quantidades percentuais mínimas da dieta ou na digesta, assim como sobre metodologias de determinação em laboratório. Entretanto, em decorrência das necessidade de novos indicadores e de técnicas confiáveis para se estimar a digestibilidade sob quaisquer condições de manejo, foram quantificados os teores de cutina nos alimentos, na digesta abomasal e nas fezes para determinação das quantidades médias diárias de matéria seca nos compartimentos do trato digestivo.

$\mathrm{Na}$ maioria dos estudos, tem-se utilizado o óxido de cromo $\left(\mathrm{Cr}_{2} \mathrm{O}_{3}\right)$ para estimação desses fluxos (Silva \& Leão, 1979). Entretanto, todos os indicadores internos ou externos, apresentam vantagens e desvantagens, físicas e/ou químicas, muito peculiares. Valadares Filho et al. (1985) afirmaram que os indicadores externos, como o óxido de cromo, e internos, como a lignina, não são totalmente recuperados nas digestas, o que ocasiona erros nas quantificações dos fluxos de matéria seca. Zeoula et al. (1994) concluíram que a lignina das forragens novas pode ser parcialmente digerida ao longo do trato gastrintestinal dos animais ruminantes, provocando supervalorização dos valores nutritivos de produtos ou rações.

Estudos têm sido realizados também com outros indicadores, principalmente os internos, como a fibra em detergente neutro indigestível (FDNI), as cinzas insolúveis em ácido (CIA) e em detergente ácido (CIDA) (Zeoula et al. 2002) e a fibra em detergente ácido indigestível (FDAI) (Zeoula et al., 2002; Ítavo et al., 2002), demonstrando que cada indicador tem suas limitações específicas. Segundo Silva \& Leão (1979), a maior vantagem no uso dos indicadores internos consiste em sua ocorrência natural nos alimentos, o que reduz os problemas relacionados à variação na excreção fecal. Todavia, mesmo quando considerados indigestíveis no trato gastrintestinal dos ruminantes, pode ocorrer recuperação incompleta do indicador, seja de ordem quantitativa na ingesta ou na digesta, seja devido à precisão de determinações químicas em laboratório. Portanto, são necessários estudos sobre compostos químicos, sobretudo aqueles contidos na parede celular e com potencial para ser utilizado como indicadores, e técnicas para estimativa das digestibilidades total e parcial dos componentes ou de nutrientes em animais ruminantes.

Este trabalho foi realizado com o objetivo de quantificar as taxas de digestão de MS, MO, PB, FDN, FDA e CNF no rúmen, no intestino e no trato digestivo total, utilizando-se a cutina como indicador do fluxo diário de matéria seca nas fezes e na digesta do abomaso.

\section{Material e Métodos}

O experimento foi conduzido nas dependências do Departamento de Zootecnia da Faculdade de Ciências Agrárias e Veterinárias - FCAV/UNESP, em Jaboticabal, SP.

Foram utilizados seis novilhos mestiços Holandês $\mathrm{x}$ Zebu castrados, com 12 meses de idade e 229,9 $\pm 33,2 \mathrm{~kg}$ de peso vivo, providos de cânulas permanentes no rúmen e no abomaso, distribuídos em delineamento quadrado latino com seis tratamentos. As fístulas do rúmen e do abomaso foram lavadas diariamente com água fria e tratadas topicamente com produtos antibacterianos e larvicidas.

Os animais foram submetidos a um período de adaptação às condições de confinamento, em baias individuais $(2,00 \times 1,10 \mathrm{~m})$ com piso de concreto, providas de cochos e de bebedouros com nível de água controlado por bóia, e receberam ivermectina para combate de endo e ectoparasitos, antes de se iniciar a fase experimental e a cada 42 dias.

Os animais foram pesados individualmente ao término de cada período de 25 dias, para ajuste do consumo inicial de matéria seca, quando necessário.

$\mathrm{Na}$ formulação das rações experimentais, utilizaram-se como volumoso feno de capim-coastcross (FCC) e casca de grão de soja (CS) e, como fontes suplementares de proteína, farelo de soja(FS), amiréia 72\%(AM) e farinha de subprodutos de abatedouro avícola (FSAA), além do grão de milho moído (GMM), usado para o ajuste energético (Tabela 1).

As rações, isoprotéicas (13\% de $\mathrm{PB})$, foram suplementadas com sal mineral (SM) misturado à ração concentrada a $0,7 \%$ da matéria seca (MS), para atender aos requerimentos dos novilhos em macro e micro minerais.

A composição química dos ingredientes utilizados na formulação das rações pode ser visualizada na Tabela 2 .

As rações completas foram fornecidas ad libitum, duas vezes ao dia ( 8 e $18 \mathrm{~h}$ ), de modo que as sobras nos cochos, em um período de 24 horas, se mantivessem em 5 a $10 \%$ da MS fornecida.

Cada animal, em cada período, recebeu um dos seguintes tratamentos: T1, T3 e T5, compostos de 60\% de mistura volumosa $(70 \%$ de $\mathrm{FCC}+30 \% \mathrm{CS})$ e $40 \%$ de concentrado (milho, sal mineral e FS, FSAA ou AM, respectivamente) e T2, T4 e T6, compostos de 60\% de mistura volumosa $(30 \%$ de $\mathrm{FCC}+70 \%$ de $\mathrm{CS}$ ) e $40 \%$ de concentrado (milho, sal mineral e uma das fontes de proteína).

As quantidades de MS, MO, PB, FDN, FDA e CNF presentes no rúmen foram determinadas ou estimadas a partir da composição da ingestão média de cada componente nutritivo por animal e por período experimental, conforme Coelho da Silva \& Leão (1979). 
Tabela 1- Composição química dos ingredientes nas rações estudadas $(\% \mathrm{MS})^{1}$

Table 1 - Ingredient (\%) chemical composition in the diets (\% DM)

\begin{tabular}{|c|c|c|c|c|c|c|}
\hline $\begin{array}{l}\text { Nutriente } \\
\text { Nutrient }\end{array}$ & $\begin{array}{c}\text { Feno } \\
\text { Hay }\end{array}$ & $\begin{array}{l}\text { Casca de soja } \\
\text { Soybean hulls }\end{array}$ & $\begin{array}{l}\text { Milho moído } \\
\text { Ground corn }\end{array}$ & $\begin{array}{c}\text { Farelo de soja } \\
\text { Soybean meal }\end{array}$ & $\begin{array}{c}\text { Amiréia } \\
\text { Starea }\end{array}$ & $\begin{array}{l}\text { Far. Subproduto avícola } \\
\text { Poultry by-product meal }\end{array}$ \\
\hline $\mathrm{MS}(D M)$ & 89,99 & 89,99 & 87,70 & 88,19 & 88,73 & 94,17 \\
\hline $\mathrm{PB}(C P)$ & 4,82 & 11,95 & 10,01 & 49,87 & 77,01 & 52,15 \\
\hline $\mathrm{MO}(O M)$ & 95,50 & 94,75 & 98,54 & 93,02 & 95,99 & 88,87 \\
\hline FDN $(N D F)$ & 89,56 & 77,24 & 9,40 & 26,57 & 27,47 & - \\
\hline FDA $(A D F)$ & 47,23 & 52,64 & 6,72 & 13,02 & 8,16 & - \\
\hline $\mathrm{CNF}(N F C)$ & 0,26 & 3,16 & 75,89 & 1,72 & 2,69 & - \\
\hline $\mathrm{CT}(T C)$ & 89,82 & 80,40 & 85,29 & 14,86 & 50,01 & - \\
\hline LDA $(A D L)$ & 7,55 & 1,39 & 0,25 & 0,55 & 0,24 & - \\
\hline Cutina $^{1}$ (Cutine) & 2,35 & 0,82 & - & - & - & - \\
\hline
\end{tabular}

1 Obtidos por meio de análise no LANA (laboratório de Nutrição Animal, FCA/UNESP, Jaboticabal - SP).

2 Cutina = obtida por meio de oxidação da LDA (Cutine = Obtained by ADL oxidation).

Tabela 2 - Porcentagens dos ingredientes e composição bromatológica das rações experimentais (\%MS) ${ }^{1}$

Table 2 - Percentage of the ingredients and chemical composition of the experimental diets (\%DM)

\begin{tabular}{|c|c|c|c|c|c|c|}
\hline \multirow[t]{2}{*}{$\begin{array}{l}\text { Ingrediente }{ }^{2} \\
\text { Ingredient }\end{array}$} & \multicolumn{6}{|c|}{$\begin{array}{l}\text { Ração experimental } \\
\text { Experimental diet }\end{array}$} \\
\hline & $\begin{array}{c}70: 30(\mathrm{~T} 1) \\
\text { FCC:CS }\end{array}$ & $\begin{array}{c}30: 70(\mathrm{~T} 2) \\
\text { FCC:CS }\end{array}$ & $\begin{array}{c}70: 30(\mathrm{~T} 3) \\
\text { FCC:CS }\end{array}$ & $\begin{array}{c}30: 70(\mathrm{~T} 4) \\
\text { FCC:CS }\end{array}$ & $\begin{array}{c}70: 30(\mathrm{~T} 5) \\
\mathrm{FCC}: \mathrm{CS}\end{array}$ & $\begin{array}{c}30: 70(\mathrm{~T} 6) \\
\text { FCC:CS }\end{array}$ \\
\hline $\mathrm{FCC}(\mathrm{CCH})$ & 42,0 & 18,0 & 42,0 & 18,0 & 42,0 & 18,0 \\
\hline $\mathrm{CS}(\mathrm{SH})$ & 18,0 & 42,0 & 18,0 & 42,0 & 18,0 & 42,0 \\
\hline GMM $(G C G)$ & 26,1 & 30,2 & 27,8 & 31,3 & 31,2 & 33,7 \\
\hline $\mathrm{FS}(S M)$ & 13,2 & 9,1 & - & - & - & - \\
\hline FSAA $(P B M)$ & - & - & 11,5 & 8,0 & - & - \\
\hline $\mathrm{AM}(S T)$ & - & - & - & - & 8,1 & 5,6 \\
\hline Sal mineral (Mineral salt) & 0,7 & 0,7 & 0,7 & 0,7 & 0,7 & 0,7 \\
\hline \multicolumn{7}{|c|}{$\begin{array}{l}\text { Composição química e bromatológica }{ }^{1} \\
\text { Chemical composition }^{1}\end{array}$} \\
\hline MO (OM) & 95,35 & 95,60 & 92,05 & 91,79 & 95,07 & 95,78 \\
\hline $\mathrm{PB}(C P)$ & 13,60 & 13,70 & 13,20 & 12,90 & 12,90 & 13,90 \\
\hline FDN $(N D F)$ & 61,75 & 59,92 & 61,54 & 60,17 & 61,67 & 57,58 \\
\hline $\mathrm{FDA}(A D F)$ & 31,65 & 33,25 & 31,38 & 32,44 & 31,34 & 32,59 \\
\hline CNF (NFC) & 21,10 & 22,77 & 15,77 & 16,38 & 19,89 & 23,21 \\
\hline LDA $(A D L)$ & 3,53 & 2,06 & 4,26 & 3,00 & 3,56 & 2,07 \\
\hline Cutina (Cutine) & 1,20 & 0,81 & 1,20 & 0,81 & 1,20 & 0,84 \\
\hline
\end{tabular}

${ }_{1}^{1}$ Dados obtidos por meio de análise no LANA (laboratório de Nutrição Animal, FCA/UNESP, Jaboticabal - SP).

2 Feno de coastcross (FCC), casca de soja (CS), grão de milho moído (GMM), farelo de soja (FS), farinha de subproduto de abatedouro avícola (FSSA) e amiréia (AM).

$3 \mathrm{CNF}=\mathrm{MO}-\left[\mathrm{FDN}+\mathrm{EE}+\left(\mathrm{PB}-\left(\mathrm{NIDA}^{*} 6,25\right)\right)\right]$.

1 Data obtained by analysis at LANA (Animal Nutrition Laboratory, FCA/UNESP, Jaboticabal-SP).

2 Coastcross hay $(C C H)$, soybean hulls $(S H)$, ground corn grain (GCG), soybean meal (SM), poultry by-product meal (PBM), and starea (ST).

${ }^{3} N F C=O M-\left[N D F+E E+\left(C P-\left(A D I N^{*} 6.25\right)\right)\right]$.

Como indicador interno, utilizou-se a cutina, segundo fórmulas citadas por Valadares Filho et al. (1985) para estimava da quantidade de matéria seca nas fezes e que passava pelo abomaso em um período de 24 horas.

Após o período de adaptação, foram retiradas amostras da digesta do abomaso e das fezes no primeiro (às $8 ; 16$; e $00 \mathrm{~h}$ ); no segundo (às $10 ; 18 ; \mathrm{e} 2 \mathrm{~h}$ ); no terceiro (às $12 ; 20$; e 4 h); e no quarto dia (às 14; 22; e 6 h).

As amostras individuais consistiram de $300 \mathrm{~mL}$ de digesta do abomaso e $150 \mathrm{~g}$ de fezes, que foram acondicionados em congelador até o final do período experimental.

Após o descongelamento, as amostras individuais da digesta foram homogeneizadas em batedeira manual do tipo Mixer (Hand Blender), retirando-se alíquotas de $150 \mathrm{~mL}$ com aproximadamente $180 \mathrm{~g}$, que foram acondicionadas em vasilhames de vidros tipo Pirex e secas a $55 \pm 5^{\circ} \mathrm{C}$ em estufas de circulação forçada, por 96 horas. Em seguida, as amostras foram retiradas dos vasilhames, acondicionadas em sacos plásticos e, posteriormente, trituradas em moinho com peneira de crivos de $1 \mathrm{~mm}$, reservando-se $2 \mathrm{~g}$ de cada amostra individual, que foram misturados, formando uma amostra composta por animal e por período.

As amostras das fezes, após o descongelamento, foram misturadas e homogeneizadas manualmente, retirando-se uma alíquota de $200 \mathrm{~g}$ por animal e por período, que foi 
colocada em vasilhame de alumínio tipo marmitex e secas em estufa decirculação forçada a $55 \pm 5^{\circ} \mathrm{C}$, por 72 horas. Todas as amostras compostas foram trituradas em moinho com peneira de crivos de $1 \mathrm{~mm}$ e armazenadas em frascos de vidro com tampa, para posteriores análises laboratoriais.

Nas amostras do feno, da casca de soja, das rações concentradas, das sobras, das digestas do abomaso e das fezes foram determinados os teores de MS, MM, PB, FDN e FDA, de acordo com metodologias descritas por Silva \& Queiroz (2002), enquanto os teores de cutina foram quantificados a partir da lignina em detergente ácido, conforme sugestões preconizadas por Fukushima \& Dehority (1995).

Os dados obtidos foram submetidos à análise de variância (ANOVA), segundo o modelo: $Y_{i j k l}=\mu+a_{i}+p_{j}$ $+\mathrm{f}_{\mathrm{k}}+\mathrm{c}_{1}+\mathrm{fc}_{\mathrm{kl}}+\mathrm{e}_{\mathrm{ijk} \mathrm{k}}$, pelo procedimento GLM do SAS ${ }^{\mathbb{R}}$ (1990), utilizando-se teste Tukey para cálculo das diferenças entre médias.

\section{Resultados e Discussão}

Os totais médios diários de MS, MO, FDN e FDA presentes no rúmen, no abomaso e nas fezes não foram afetados pelas fontes de nitrogênio estudadas (Tabela 3 ).

No entanto, a amiréia (AM), semelhante ao farelo de soja, proporcionou maiores quantidades de CNF presentes no rúmen que a farinha de subprodutos de abatedouro avícola (FSAA).

As quantidades de MS, MO, FDN e FDA presentes no abomaso e nas fezes estimadas com o uso de cutina foram maiores que aquelas registradas por Silva et al. (2002), ao avaliarem as mesmas variáveis usando lignina como indicador.

As fontes de nitrogênio não afetaram os coeficientes de digestibilidade aparente de MS, MO, PB, FDN e FDA no trato digestivo total (Tabela 4). A FSAA, por sua vez, proporcionou maiores digestibilidades de FDN e FDA no rúmen que a $\mathrm{AM}$, mas foi semelhante ao farelo de soja (FS). As maiores digestões dos CNF no intestino dos bovinos alimentados com AM como fonte de nitrogênio que naqueles

Tabela 3 - Efeitos das fontes protéicas sobre as quantidades médias diárias de MS, MO, PB, FDN, FDA e CNF ingeridas, presentes no abomaso e nas fezes

Table 3 - Effects of crude protein sources on the average daily amounts of DM, OM, NDF,ADF, and NFC consumed and present in the abomasum and feces

\begin{tabular}{lc}
\hline Item & Fonte protéica \\
Item & Protein source
\end{tabular}

Item

Protein source

FS $(S M) \quad$ AM $(S T) \quad$ FSAA $(P B M)$

\begin{tabular}{|c|c|c|c|c|}
\hline & $\mathrm{FS}(S M)$ & $\mathrm{AM}(S T)$ & ESAA $(P B M)$ & $\mathrm{CV}$ \\
\hline \multicolumn{5}{|c|}{ MS (g/dia) $-D M(g / d a y)$} \\
\hline Ingerido (Consumed) & $6750^{\mathrm{a}}$ & $7104^{\mathrm{a}}$ & $7376^{\mathrm{a}}$ & 16,3 \\
\hline Abomaso (Abomasum) & $3876^{\mathrm{a}}$ & $4731^{\mathrm{a}}$ & $3880^{\mathrm{a}}$ & 27,8 \\
\hline Fezes (Feces) & $3055^{\mathrm{a}}$ & $3206^{\mathrm{a}}$ & $2998^{a}$ & 31,5 \\
\hline \multicolumn{5}{|c|}{ MO (g/dia) - OM (g/day) } \\
\hline Ingerido (Consumed) & $6446^{\mathrm{a}}$ & $6815^{\mathrm{a}}$ & $7019^{a}$ & 16,4 \\
\hline Abomaso (Abomasum) & $3028^{a}$ & $3735^{\mathrm{a}}$ & $3069^{a}$ & 28,9 \\
\hline Fezes (Feces) & $2784^{\mathrm{a}}$ & $2956^{\mathrm{a}}$ & $2727^{\mathrm{a}}$ & 28,9 \\
\hline \multicolumn{5}{|c|}{$\mathrm{PB}$ (g/dia) $-C P(g /$ day $)$} \\
\hline Ingerido (Consumed) & $753^{a}$ & $806^{\mathrm{a}}$ & $846^{\mathrm{a}}$ & 17,6 \\
\hline Abomaso (Abomasum) & $696^{\mathrm{a}}$ & $864^{\mathrm{a}}$ & $780^{\mathrm{a}}$ & 27,6 \\
\hline Fezes (Feces) & $459^{\mathrm{a}}$ & $488^{\mathrm{a}}$ & $457^{\mathrm{a}}$ & 35,6 \\
\hline \multicolumn{5}{|c|}{$\mathrm{FDN}(\mathrm{g} / \mathrm{dia})-N D F(g /$ day $)$} \\
\hline Ingerido (Consumed) & $4078^{a}$ & $4194^{\mathrm{a}}$ & $4668^{a}$ & 15,9 \\
\hline Abomaso (Abomasum) & $1717^{\mathrm{a}}$ & $2082^{\mathrm{a}}$ & $1651^{\mathrm{a}}$ & 28,6 \\
\hline Fezes (Feces) & $1982^{\mathrm{a}}$ & $2059^{\mathrm{a}}$ & $1854^{\mathrm{a}}$ & 32,8 \\
\hline \multicolumn{5}{|c|}{ FDA (g/dia) $-A D F(g / d a y)$} \\
\hline Ingerido (Consumed) & $2151^{\mathrm{a}}$ & $2235^{\mathrm{a}}$ & $2311^{\mathrm{a}}$ & 17,4 \\
\hline Abomaso (Abomasum) & $1442^{\mathrm{a}}$ & $1710^{\mathrm{a}}$ & $1444^{\mathrm{a}}$ & 27,1 \\
\hline Fezes (Feces) & $1084^{\mathrm{a}}$ & $1150^{\mathrm{a}}$ & $1027^{\mathrm{a}}$ & 30,6 \\
\hline \multicolumn{5}{|c|}{$\mathrm{CNF}(\mathrm{g} / \mathrm{dia})-N F C(g / d a y)$} \\
\hline Ingerido (Consumed) & $1423,7^{a b}$ & $1634,6^{\mathrm{a}}$ & $1216,9^{b}$ & 18,1 \\
\hline Abomaso (Abomasum) & $810,0^{b}$ & $1207,2^{\mathrm{a}}$ & $880,8^{a b}$ & 35,5 \\
\hline Fezes (Feces) & $457,8^{\mathrm{a}}$ & $511,5^{\mathrm{a}}$ & $549,8^{a}$ & 37,3 \\
\hline
\end{tabular}

Médias seguidas de letras iguais na mesma linha não diferem $(P>0,05)$ estatisticamente pelo teste Tukey. Means followed by the same letters in the same row did not differ $(P>0.05)$ by Tukey test. 
que receberam FS e AM, provavelmente em razão dos maiores fluxos deste componente não-digerido no rúmen.

Os valores de digestibilidade aparente total da MS deste trabalho foram semelhantes aos $58,18 \%$ obtidos por Ítavo et al. (2002), em rações com 50\% de concentrado utilizando óxido de cromo como indicador. Entretanto, Berchielli et al. (2000) avaliaram vários indicadores em estudos com rações com $45 \%$ de concentrado e obtiveram valores ligeiramente superiores.

As digestibilidades da MS, FDN e FDA das rações com farinha de subproduto de abatedouro avícola (Tabela 4) no rúmen foram semelhantes às observadas no farelo de soja, porém superiores $(\mathrm{P}<0,05)$ às da amiréia. Estes resultados são coerentes com aqueles verificados nos ensaios de degradabilidade, quando detectadas elevadas frações solúveis (A) da farinha de subproduto de abatedouro avícola e menores teores das demais frações (Silva et al. 1999).

Observou-se que a digestibilidade intestinal da FDN foi praticamente nula e não diferiu entre as fontes de nitrogênio (Tabela 4). Estes resultados são semelhantes aos divulgados na literatura, confirmando, neste caso, que a FDN indigestível pode ser usada como indicador interno em testes de digestibilidade no rúmen, no intestino e no trato digestivo total de bovinos.

As fontes de nitrogênio não afetaram as digestibilidades da proteína bruta no trato digestivo total, no rúmen e nos intestinos. No entanto, os coeficientes de digestibilidade aparente no rúmen para $\mathrm{PB}$ apresentaram valores baixos ( $7,57 \%$ para $\mathrm{FS} ; 7,80 \%$ para FSAA e $7,20 \%$ negativo para $\mathrm{AM}$ ), demonstrando que pode não ter ocorrido perdas de nitrogênio na forma de amônia, o que, conforme afirmativa de Ladeira et al. (1999), citado por Itavo et al. (2002), seria indicativo de deficiência protéica na dieta. Porém, pode-se afirmar que as rações sendo isoprotéicas e isoenergéticas e pelos níveis de fermentação da matéria orgânica no rúmen, $o$ mais provável é que tenha ocorrido maior síntese de proteína microbiana neste compartimento digestivo. Por outro lado, o coeficiente de variação foi muito elevado, o que pode ser devido a fatores como: metodologia de determinação dos teores de cutina, níveis inadequados nas amostras para

Tabela 4 - Efeitos das fontes protéicas sobre o coeficiente de total das digestões aparente total, ruminal e intestinal da MS, MO, PB, FDN, FDA e CNF 1

Table 4 - Effects of the protein source on the apparent total tract, ruminal and intestinal digestibilities of DM, OM, CP, NDF, ADF, and NFC1

\begin{tabular}{|c|c|c|c|c|}
\hline \multirow[t]{2}{*}{$\begin{array}{l}\text { Item } \\
\text { Item }\end{array}$} & \multicolumn{3}{|c|}{$\begin{array}{c}\text { Fonte protéica } \\
\text { Protein source }\end{array}$} & \multirow[b]{2}{*}{$\mathrm{CV}$} \\
\hline & $\mathrm{FS}(S M)$ & $\mathrm{AM}(S T)$ & FSAA $(P B M)$ & \\
\hline \multicolumn{5}{|c|}{ MS $(\%)-D M(\%)$} \\
\hline Total (Total) & $54,74^{\mathrm{a}}$ & $54,87^{\mathrm{a}}$ & $59,36^{\mathrm{a}}$ & 17,7 \\
\hline Ruminal $^{2}$ (Ruminal) $^{2}$ & $42,58^{a b}$ & $33,40^{\mathrm{b}}$ & $47,40^{\mathrm{a}}$ & 31,5 \\
\hline Intestinal $^{2}$ (Intestinal) $^{2}$ & $12,16^{\mathrm{a}}$ & $21,47^{\mathrm{a}}$ & $11,96^{\mathrm{a}}$ & 48,2 \\
\hline \multicolumn{5}{|c|}{ MO (\%) - OM (\%) } \\
\hline Total (Total) & $56,80^{\mathrm{a}}$ & $56,62^{\mathrm{a}}$ & $61,15^{\mathrm{a}}$ & 16,4 \\
\hline Ruminal $^{2}$ (Ruminal) $^{2}$ & $53,02^{\mathrm{a}}$ & $45,19^{\mathrm{a}}$ & $56,28^{a}$ & 20,9 \\
\hline Intestinal $^{2}{\text { (Intestinal })^{2}}^{2}$ & $3,78^{\mathrm{a}}$ & $11,43^{\mathrm{a}}$ & $4,87^{\mathrm{a}}$ & 106,7 \\
\hline \multicolumn{5}{|c|}{ PB (\%) - CP (\%) } \\
\hline Total (Total) & $39,04^{\mathrm{a}}$ & $39,45^{\mathrm{a}}$ & $45,98^{\mathrm{a}}$ & 38,6 \\
\hline Ruminal $^{2}$ (Ruminal $^{2}$ & $7,57^{\mathrm{a}}$ & $-7,20^{\mathrm{a}}$ & $7,80^{\mathrm{a}}$ & 2830,7 \\
\hline Intestinal $^{2}{\text { (Intestinal })^{2}}^{2}$ & $31,47^{\mathrm{a}}$ & $49,93^{\mathrm{a}}$ & $38,18^{a}$ & 38,4 \\
\hline \multicolumn{5}{|c|}{ FDN (\%) - NDF (\%) } \\
\hline Total (Total) & $51,40^{\mathrm{a}}$ & $50,91^{\mathrm{a}}$ & $60,28^{\mathrm{a}}$ & 20,1 \\
\hline Ruminal $^{2}$ (Ruminal) $^{2}$ & $57,90^{\mathrm{ab}}$ & $50,36^{\mathrm{b}}$ & $64,63^{a}$ & 17,4 \\
\hline Intestinal $^{2}$ (Intestinal) $^{2}$ & $-6,50^{\mathrm{a}}$ & $0,55^{\mathrm{a}}$ & $-4,35^{a}$ & 203,2 \\
\hline \multicolumn{5}{|c|}{ FDA $(\%)-A D F(\%)$} \\
\hline Total (Total) & $49,63^{\mathrm{a}}$ & $48,55^{\mathrm{a}}$ & $55,56^{\mathrm{a}}$ & 21,2 \\
\hline Ruminal $^{2}$ (Ruminal) $^{2}$ & $32,99^{a b}$ & $23,49^{b}$ & $37,52^{\mathrm{a}}$ & 53,8 \\
\hline Intestinal $^{2}$ (Intestinal $^{2}$ & $16,64^{\mathrm{a}}$ & $25,06^{\mathrm{a}}$ & $18,04^{\mathrm{a}}$ & 39,9 \\
\hline \multicolumn{5}{|c|}{$\mathrm{CNF}(\%)-N F C(\%)$} \\
\hline Total (Total) & $67,84^{\mathrm{a}}$ & $68,71^{\mathrm{a}}$ & $54,87^{b}$ & 17,7 \\
\hline Ruminal $^{2}$ (Ruminal $^{2}$ & $43,11^{\mathrm{a}}$ & $24,15^{b}$ & $27,62^{b}$ & 31,5 \\
\hline Intestinal $^{2}$ (Intestinal) $^{2}$ & $24,74^{b}$ & $42,56^{\mathrm{a}}$ & $27,25^{b}$ & 48,2 \\
\hline
\end{tabular}

Médias seguidas de letras iguais na mesma linha não diferem $(P>0,05)$ pelo teste Tukey.

Means followed by the same letters in the same row did not differ $(P>0.05)$ by Tukey test. 
maiores precisões de quantificações em laboratório e/ou inconstância de seus teores nos fluxos.

Constam na Tabela 5 as médias dos coeficientes de digestibilidade dos componentes nutritivos, conforme o local de digestão, e dos níveis de casca de soja em substituição ao feno.

As fontes protéicas não tiveram efeitos sobre as quantidades médias diárias de MS, MO, FDN, FDA e PB ingeridas

Tabela 5 - Efeitos dos níveis de casca de soja sobre os coeficientes de digestibilidades aparente da MS, MO, PB, FDN, FDA e de CNF Table 5 - Effects soybean hull level on the total, ruminal and intestinal apparent digestibilities of DM, CP, NDF, ADF, and NFC

\begin{tabular}{|c|c|c|c|c|c|c|}
\hline \multirow[t]{2}{*}{$\begin{array}{l}\text { Nível } \\
\text { Level }^{1}\end{array}$} & \multicolumn{5}{|c|}{$\begin{array}{l}\text { Digestibilidade aparente no trato digestivo total (\%) } \\
\text { Apparent digestibility in the total digestive tract }(\%)\end{array}$} & \multirow[b]{2}{*}{$\mathrm{CNF}(N F C)$} \\
\hline & $\mathrm{MS}(D M)$ & $\mathrm{MO}(O M)$ & $\mathrm{PB}(C P)$ & $\mathrm{FDN}(N D F)$ & FDA $(A D F)$ & \\
\hline 1 & $49,7^{\mathrm{b}}$ & $51,7^{b}$ & $31,3^{\mathrm{b}}$ & $48,6^{b}$ & $42,9^{b}$ & $52,6^{\mathrm{b}}$ \\
\hline 2 & $62,6^{\mathrm{a}}$ & $64,4^{\mathrm{a}}$ & $49,8^{\mathrm{a}}$ & $59,9^{\mathrm{a}}$ & $58,7^{\mathrm{a}}$ & $72,8^{\mathrm{a}}$ \\
\hline \multicolumn{7}{|c|}{$\begin{array}{l}\text { Digestibilidade aparente no rúmen (\%) } \\
\text { Ruminal apparent digestibility (\%) }\end{array}$} \\
\hline 1 & $33,6^{b}$ & $45,7^{b}$ & $-6,4^{\mathrm{a}}$ & $52,5^{b}$ & $19,1^{b}$ & $20,4^{b}$ \\
\hline 2 & $47,2^{\mathrm{a}}$ & $56,3^{\mathrm{a}}$ & $8,5^{\mathrm{a}}$ & $62,0^{\mathrm{a}}$ & $38,2^{\mathrm{a}}$ & $37,5^{\mathrm{a}}$ \\
\hline \multicolumn{7}{|c|}{$\begin{array}{c}\text { Digestibilidade aparente nos intestinos (\%) } \\
\text { Intestinal apparent digestibility (\%) }\end{array}$} \\
\hline 1 & $27,7^{\mathrm{a}}$ & $9,2^{\mathrm{a}}$ & $33,1^{b}$ & $-12,1^{\mathrm{a}}$ & $27,3^{\mathrm{a}}$ & $39,4^{b}$ \\
\hline 2 & $27,6^{\mathrm{a}}$ & $17,0^{\mathrm{a}}$ & $44,8^{\mathrm{a}}$ & $-7,7^{\mathrm{a}}$ & $31,6^{\mathrm{a}}$ & $52,3^{\mathrm{a}}$ \\
\hline
\end{tabular}

Médias na mesma coluna para o mesmo local de digestão entre níveis seguidas de letras iguais não diferem ( $P>0,01)$, pelo teste Tukey.

${ }^{1}$ Niveis de casca de soja em substituição ao feno de coastcross.

Means within the same column, in the same digestion site, followed by same letters did not differ $(P>0.01)$ by Tukey test.

${ }_{1}^{1}$ Levels of soybean hulls that replaced coastcross hay.

no abomaso e nas fezes. A digestibilidade da MS das rações com $70 \%$ de casca de soja em substituição ao feno de coastcross foram maiores $(\mathrm{P}<0,05)$ no trato digestivo total e no rúmen que aquelas observadas com as rações com $30 \%$. Todavia, considerando-se a lignina um indicadorreferência, Silva et al. (2002) relataram que a cutina minimizou as digestibilidades da MS nos três locais do trato digestivo, como resultado da técnica de determinação da cutina, que subvalorizou a digestibilidade da MS nos compartimentos subseqüentes, maximizando as frações indigestíveis.

Os coeficientes de digestibilidade da MS, MO, FDN e FDA no trato digestivo total e no rúmen das rações contendo $70 \%$ de casca de soja em substituição ao feno de coastcross foram maiores $(\mathrm{P} \leq 0,05)$ que os daquelas contendo $30 \%$ de casca de soja. Entretanto, não foram observados efeitos nas taxas de digestão da $\mathrm{PB}$ no rúmen e da MS, MO, FDN e FDA nos intestinos dos animais alimentados com 30 ou $70 \%$ de casca de soja em substituição ao feno.

Estas observações confirmam as obtidas por Silva et al. (1999), que registraram alta degradabilidade ruminal dos componentes nutritivos da casca de soja.

Os teores de MS, MO, FDN e FDA que chegaram nos intestinos tiveram digestões semelhantes entre os níveis de casca de soja em cada um dos compartimentos digestivos, porém, foram menores que aqueles observados com a lignina.

\section{Conclusões}

A cutina apresentou potencial como indicador interno para o cálculo dos coeficientes de digestibilidade dos componentes nutricionais das rações utilizadas neste trabalho. Recomenda-se a realização de outros experimentos visando definir as quantificações mínima e máxima deste indicador nas rações e estudar suas correlações com coleta total de fezes e outros indicadores como FDNi, FDAi e $\mathrm{Cr}_{2} \mathrm{O}_{3}$ nas condições in vitro e in situ.

\section{Literatura Citada}

BERCHIELLI, T.T.; ANDRADE, P.; FURLAN, C.L. Avaliaçãode indicadores internos em ensaios de digestibilidade. Revista Brasileira de Zootecnia, v.29, n.3, p.830-833, 2000.

FUKUSHIMA, R.S.; DEHORITY, B.A. Modificação do método colorimétrico "lignina solúvel em brometo de acetila" na estimativa quantitativa da lignina. Revista Brasileira de Zootecnia, v.24, p.192-203, 1995.

ÍTAVO, L.C.V.; VALADARES FILHO, S.C.; SILVA, F.F. et al. Comparação de indicadores e metodologia de coleta para estimativas de produção fecal e fluxo de digesta em bovinos. Revista Brasileira de Zootecnia, v.31, n.4, p.1833-1839, 2002.

STATISTICAL ANALYSES SYSTEM - SAS. SAS ${ }^{\circledR}$. User's guide: statistics. 4.ed. Cary: 1990. 956p.

SILVA, D.J.; QUEIROZ, A.C. Análises de alimentos: (métodos químicos e biológicos). 3.ed. Viçosa, MG: Universidade Federal de Viçosa, 2002, 235p.

SILVA, J.F.C.; LEÃO, M.I. Fundamentos de nutrição dos ruminantes. Piracicaba: Livroceres, 1979. 380p.

SILVA, L.D.F.; EZEQUIEL, J.M.B.; AZEVEDO, P.S. et al. Digestão total e parcial de alguns components de dietas contendo diferentes 
níveis de casca de soja e fontes de nitrogênio, em bovinos. Revista Brasileira de Zootecnia, v.31, n.3, p.1258-1268, 2002.

SILVA, L.D.F.; EZEQUIEL, J.M.B.; AZEVEDO, P.S. et al. Degradabilidade ruminal in situ da matéria seca, matéria orgânica e da proteína bruta de alguns alimentos em novilhos. Semina Ciência Agrária, v.20, n.1, p.25-30, 1999.

VALADARES FILHO, S.C.; SILVA, J.F.C.; LEÃO, M.I. et al. Óxido crômico e lignina na determinação dos fluxos de matéria seca abomasal, ileal e fecal em bovinos e bubalinos. Revista Brasileira de Zootecnia, v.14, n.5, p.565-574, 1985.
ZEOULA, L.M.; BORGES, I.; BRANCO, A.F. et al. Avaliação de indicadores em estudo de digestibilidade de alimento para ruminantes. Revista Unimar, v.16, supl. 1, p.137-152, 1994. ZEOULA, L.M.; PRADO, I.N.; DIAN, P.H.M. et al. Recuperação fecal de indicadores internos avaliados em ruminantes. Revista Brasileira de Zootecnia, v.31, n.4, p.1865-1874, 2002.

Recebido: 28/02/05 Aprovado:04/08/05 